\title{
Conservation bottom-up initiatives in marine recreational spearfishing suggest the emergence of positive attitudes towards conservation
}

\author{
Valerio Sbragaglia ${ }^{1}$, Robert Arlinghaus ${ }^{2,3}$ \\ ${ }^{1}$ Institut de Ciències del Mar, CSIC, Passeig Marítim de la Barceloneta 37-49, 08003, Barcelona, Spain. \\ (VS) (Corresponding author) E-mail: valeriosbra@ gmail.com. ORCID iD: https://orcid.org/0000-0002-4775-7049 \\ ${ }^{2}$ Department of Biology and Ecology of Fishes, Leibniz-Institute of Freshwater Ecology and Inland Fisheries, \\ Müggelseedamm 310, 12587 Berlin, Germany. \\ (RA) E-mail: arlinghaus@igb-berlin.de. ORCID iD: https://orcid.org/0000-0003-2861-527X \\ ${ }^{3}$ Division of Integrative Fisheries Management, Department of Crop and Animal Sciences, Faculty of Life Sciences, \\ Humboldt-Universität zu Berlin, Philippstrasse 13, Haus 7, 10115 Berlin, Germany.
}

\begin{abstract}
Summary: We show that marine recreational spearfishers voluntarily organize bottom-up conservation actions. The main goals of these actions are to provide support to research in monitoring fish assemblages, tracking biological invasions or mitigating impacts on the environment, such as those stemming from pollution and littering. We show that such initiatives started more than 20 years ago and are now facilitated by social media networking. We argue that the emergence of bottomup conservation actions in marine recreational spearfishers should be encouraged, supported and integrated into participatory management plans. This is important to mitigate the potential negative impacts of marine recreational spearfishing and to catalyse broader civil actions for conservation of marine ecosystems.
\end{abstract}

Keywords: recreational fishing; citizen science; plastic pollution; participatory management.

Las iniciativas de conservación "bottom-up" en la pesca submarina recreativa sugieren el desarrollo de actitudes positivas hacia la conservación

Resumen: Los pescadores submarinos recreativos organizan voluntariamente acciones "bottom-up" de conservación del medio ambiente. Los principales objetivos de estas acciones son apoyar a la investigación en el monitoreo de los ecosistemas marinos, detectar especies invasoras o mitigar los impactos sobre el medio ambiente, como los derivados de la contaminación y la basura. Tales iniciativas comenzaron hace más de 20 años y hoy en día podrían ser facilitadas por las redes sociales. El desarrollo de acciones de conservación "bottom-up" en los pescadores submarinos recreativos deben ser alentadas, apoyadas e integradas en los planes de manejo participativo. Esto es importante para mitigar los potenciales impactos negativos de la pesca submarina recreativa y para catalizar acciones civiles más amplias para la conservación de los ecosistemas marinos.

Palabras claves: pesca recreativa; ciencia ciudadana; contaminación plástica; manejo participativo.

Citation/Como citar este artículo: Sbragaglia V., Arlinghaus R. 2020. Conservation bottom-up initiatives in marine recreational spearfishing suggest the emergence of positive attitudes towards conservation. Sci. Mar. 84(4): 441-444. https://doi. org/10.3989/scimar.05139.05A

Editor: F. Peters.

Received: October 18, 2020. Accepted: November 4, 2020. Published: November 19, 2020.

Copyright: (c) 2020 CSIC. This is an open-access article distributed under the terms of the Creative Commons Attribution 4.0 International (CC BY 4.0) License.

\section{REPRESENTATIVENESS OF MARINE RECREATIONAL SPEARFISHING}

Marine recreational spearfishing may have a series of negative ecological impacts on ecosystems (Lewin et al. 2019). Such impacts can be related to selective harvesting of large individuals (Pavlowich and Kapuscinski
2017), long-lived and slow-growing species (e.g. Lloret et al. 2008, Giglio et al. 2017), as well as selection based on life-history and behavioural traits (e.g. JanuchowskiHartley et al. 2011, Lindfield et al. 2014, Sbragaglia et al. 2018). At the same time, marine recreational spearfishers can have positive attitudes towards conservation actions; for example, Assis et al. (2018) showed that web- 
surveyed Portuguese recreational spearfishers believe that marine protected areas are important for the conservation of marine ecosystems. In this context, a proper representation of marine recreational spearfishers-e.g. federations, organizations or clubs-is key in fostering and promoting proactive behaviours related to conservation as well as to management (Arlinghaus et al. 2019). This is also important for education of new generations of spearfishers and creating bridges between researchers and conservationists (Arlinghaus et al. 2019). Marine recreational spearfishers are a minority; for example, they represent less than $10 \%$ of all marine recreational fishers in Spain and Portugal (Gordoa et al. 2019, Diogo et al. 2020). Moreover, spearfishers are generally poorly represented within fisher organizations. Spanish and Italian marine recreational spearfishers are mainly represented by sports federations, but only about half of them are members (e.g. as observed in Spain; Gordoa et al. 2019). Therefore, a non-negligible proportion of marine recreational spearfishers lack representation, which could prevent their positive attitudes towards conservation from being extended to policy-making. However, see Sbragaglia et al. (2016) for an example of involvement of spearfishers through NGOs.

Here, we provide evidence of conservation bottomup initiatives of marine recreational spearfishers. We highlight that positive attitudes towards conservation were already formed more than 20 years ago and that social media could now facilitate the emergence of these collective initiatives and foster their spread across countries. We also present preliminary results regarding spearfisher-induced conservation actions, suggesting that, if properly integrated into adaptive participatory management, such initiatives could foster and reinforce the sustainable development of marine recreational spearfishing.

\section{SEA SENTINELS}

In 1997 a pioneering Italian spearfisher from Sardinia created the Italian Association of Spearfishing (IAS) with the aim of representing all recreational fishers who were not interested in sports spearfishing and were therefore not members of the national sports fishing association. After five years of activity, the IAS had over 3000 members from 89 different Italian provinces and launched a pioneering project for that time: Sea Sentinels. The main goal of the project was to provide support to research in monitoring fish assemblages, tracking biological invasions and restoring the environment from pollution such as plastic debris. In other words, this association realized the value of citizen science and local ecological knowledge and the problem of plastic marine pollution back in 2002. Moreover, the IAS had the goal of increasing awareness among marine recreational spearfishers of their impact on marine ecosystems and fostering education of a new generation of recreational spearfishers. They wrote: “...the sea sentinels can be useful for the coastal community and are a cohesive factor for members, who will feel they form an active part of an important project". In summary, they advocated for participatory management.

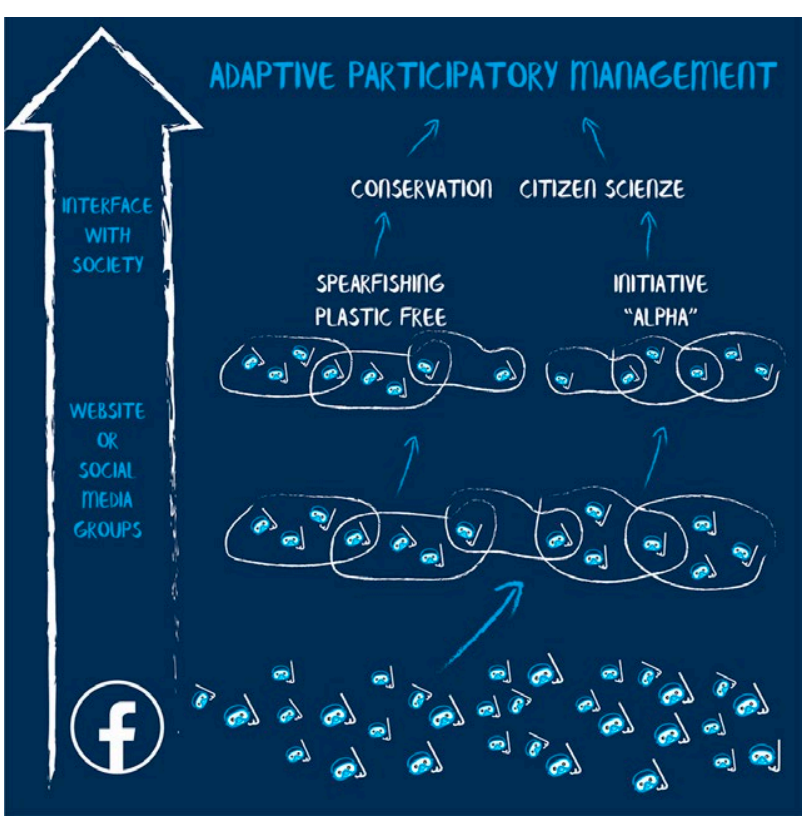

Fig. 1. - A conceptual framework showing the emergence of PlasticFree Spearfishing. The bottom-up process can be simplified as follows: $(i)$ recreational spearfishers are present as individuals on social media such as Facebook; (ii) they organize themselves in social media groups according to their interests and attitudes; (iii) social media groups are organized in a metagroup with the goal of helping to mitigate plastic pollution; (iv) they start organizing actions for removing underwater plastic debris (see also Fig. 3) and create an interface with society. Similar initiatives could also emerge for other purposes such as the citizen science initiative shown on the right side of the figure.

The IAS found support from the academic sector and established a collaboration with the University of Sassari by creating a survey that was distributed to all members. The idea was to collect information about the environment and fish assemblages during spearfishing trips. Unfortunately, the project never took off properly. At the critical moment the IAS failed to find support from the local and national governments and the initiative slowly faded out.

\section{PLASTIC-FREE SPEARFISHING}

Many aspects of human culture, knowledge and social interactions are now occurring online on social media platforms such as Facebook and YouTube (Reed 2018). Recreational spearfishers are active on social media and often organize themselves in groups according to fishing preferences (e.g. targeting a specific species), geography (e.g. specific regions within a country) and techniques (e.g. a specific spearfishing technique; Fig. 1). The digital environment triggered the emergence of a similar process to the Sea Sentinels. In 2018, several Italian marine recreational spearfishing Facebook groups decided to create an initiative called Plastic-Free Spearfishing to raise awareness among spearfishers about the problem of plastic pollution and actively contribute to cleaning the underwater environment during fishing trips. Interestingly, this initiative emerged without feedback from science or institutions (Fig. 1), as was the case with the Sea Sentinels. 


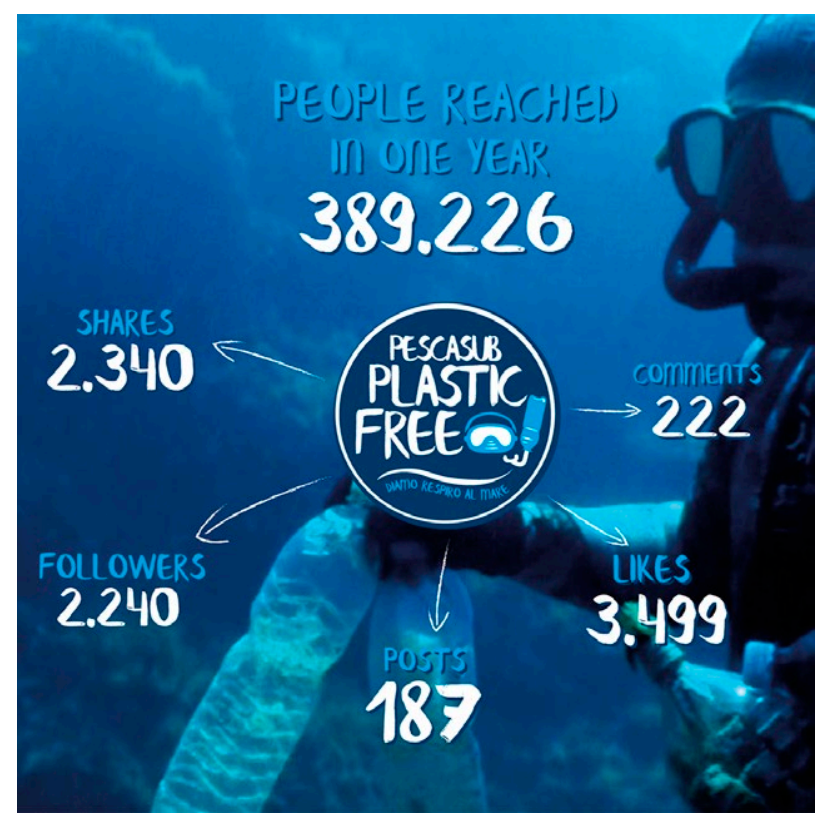

Fig. 2. - A summary of the social media impact generated by the metagroup created on Facebook by Plastic-Free Spearfishing.

In the last year Plastic-Free Spearfishing has created a metagroup on Facebook (i.e. a group created by the administrators of other groups) as well as a website (http://www.pescasubplasticfree.org). The activity of the metagroup is mainly based on posting videos and photos to increase awareness of marine plastic pollution. Overall, the metagroup reached almost 400000 people for a total of 2240 followers (Fig. 2). Moreover, they organized several actions for removal of underwater plastic debris (Fig. 3). Although the initiative started in Italy, the social media network creates international connections, and other actions of underwater plastic debris removal were organized in Spain and Tunisia (Fig. 3).

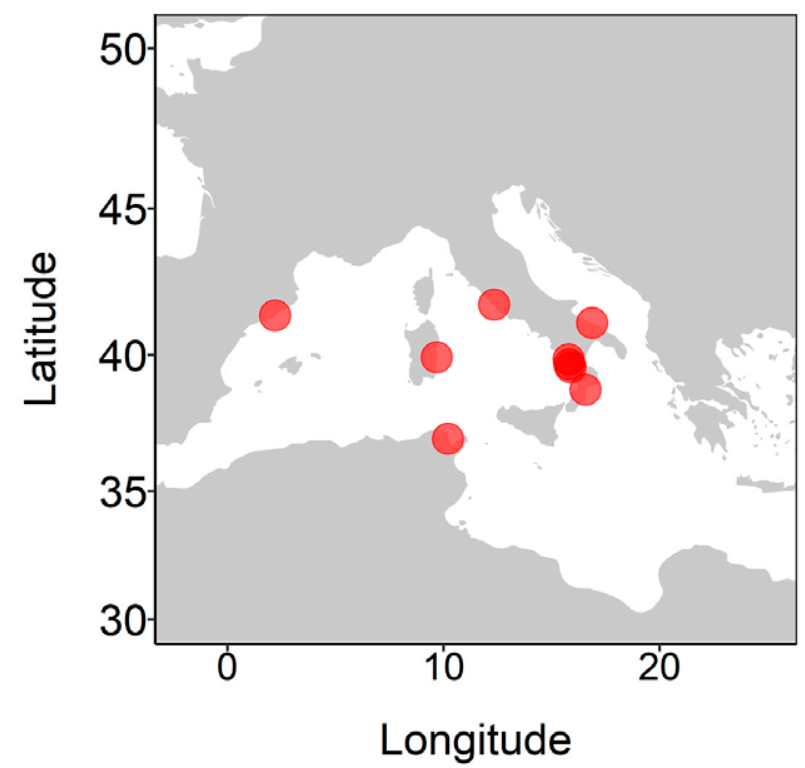

Fig. 3. - The removal of underwater plastic debris fostered or organized by Plastic-Free Spearfishing.

\section{FUTURE PERSPECTIVES}

This commentary aims to highlight three major aspects related to the human dimension of marine recreational spearfishers. The first one is that positive attitudes towards conservation were already formed more than 20 years ago and are probably now becoming more common. This hypothesis must be backed up by proper research in the future, but it is plausible to assume that marine recreational spearfishers are changing from being exclusively interested in underwater hunting to also being willing to invest time and resources in conservation actions such as those described here. A similar example has been already shown in the context of sharks and rays at the Great Barrier Reef (Whatmough et al. 2011). The second aspect is that social media are not necessary to trigger the emergence of conservation actions, but they can probably facilitate their spread across countries. The third and most important aspect is that such initiatives, in particular when they are voluntarily created by recreational spearfishers themselves, should be encouraged, supported and integrated into participatory management actions. Indeed, the emergence of voluntary and bottom-up resource-conserving actions such as the one described here provide a powerful alternative to costly institutional actions (Cooke et al. 2013, Arlinghaus et al. 2019, Fujitani et al. 2020) and may promote the development and shaping of conservation-oriented social norms. Pro-environmental social norms are important at the moment to mitigate the impacts of recreational spearfishers on the marine ecosystems and to serve as a catalyst for civil actions for broader environmental conservation of marine ecosystems facing other pressures such as habitat loss and pollution.

\section{ACKNOWLEDGEMENTS}

We are grateful to the Plastic-Free Spearfishing team (in particular Andrea Micarelli) for providing graphical illustrations and sharing their data. We are also grateful to Silvio Ferruzzi for sharing the information related to the Sea Sentinels. V.S. is supported by a Juan de la Cierva Incorporación research fellowship (IJC2018-035389-I) granted by the Spanish Ministry of Science and Innovation.

\section{REFERENCES}

Arlinghaus R., Abbott J.K., Fenichel E.P., et al. 2019. Governing the recreational dimension of global fisheries. Proc. Natl. Acad. Sci. 116: 5209-5213.

https://doi.org/10.1073/pnas.1902796116

Assis J., Gonçalves J.M.S., Veiga P., et al. 2018. Spearfishing in Portugal: A baseline study on spearfishers' profiles, habits and perceptions towards management measures. Fish. Manag. Ecol. 25: 417-428.

https://doi.org/10.1111/fme.12313

Cooke S.J., Suski C.D., Arlinghaus R., et al. 2013. Voluntary institutions and behaviours as alternatives to formal regulations in recreational fisheries management. Fish Fish. 14: 439-457. https://doi.org/10.1111/j.1467-2979.2012.00477.x

Diogo H., Veiga P., Pita C., et al. 2020. Marine recreational fishing in Portugal: Current knowledge, challenges, and future perspectives. Rev. Fish. Sci. Aquac. 28: 536-560. https://doi.org/10.1080/23308249.2020.1777083 
Fujitani M.L., Riepe C., Pagel T., et al. 2020. Ecological and social constraints are key for voluntary investments into renewable natural resources. Glob. Environ. Change 63: 102125. https://doi.org/10.1016/j.gloenvcha.2020.102125

Giglio V.J., Bender M.G., Zapelini C., et al. 2017. The end of the line? Rapid depletion of a large-sized grouper through spearfishing in a subtropical marginal reef. Perspect. Ecol. Conserv. 15: $115-118$ https://doi.org/10.1016/j.pecon.2017.03.006

Gordoa A., Dedeu A.L., Boada J. 2019. Recreational fishing in Spain: First national estimates of fisher population size, fishing activity and fisher social profile. Fish. Res. 211: 1-12. https://doi.org/10.1016/j.fishres.2018.10.026

Januchowski-Hartley F.A., Graham N.A.J., Feary D.A., et al. 2011. Fear of fishers: Human predation explains behavioral changes in coral reef fishes. Plos ONE 6: e22761. https://doi.org/10.1371/journal.pone.0022761

Lewin W.C., Weltersbach M.S., Ferter K., et al. 2019. Potential environmental impacts of recreational fishing on marine fish stocks and ecosystems. Rev. Fish. Sci. Aquac. 27: 287-330. https://doi.org/10.1080/23308249.2019.1586829

Lindfield S.J., McIlwain J.L., Harvey E.S. 2014. Depth refuge and the impacts of SCUBA spearfishing on coral reef fishes. Plos ONE 9: e92628.

https://doi.org/10.1371/journal.pone.0092628
Lloret J., Zaragoza N., Caballero D., et al. 2008. Spearfishing pressure on fish communities in rocky coastal habitats in a Mediterranean marine protected area. Fish. Res. 94: 84-91. https://doi.org/10.1016/j.fishres.2008.07.002

Pavlowich T. Kapuscinski A.R. 2017. Understanding spearfishing in a coral reef fishery: Fishers' opportunities, constraints, and decision-making. PloS ONE 12: e0181617. https://doi.org/10.1371/journal.pone.0181617

Reed T.V. 2018. Digitized lives: Culture, power and social change in the internet era. Routledge, London, $332 \mathrm{pp}$. https://doi.org/10.4324/9781315143415

Sbragaglia V., Pla O.S., Gordoa A., et al. 2016. The Barcelona agreement: a manifesto towards the spearfishing of the future. Sci. Mar. 80: 423-426. https://doi.org/10.3989/scimar.04504.01A

Sbragaglia V., Morroni L., Bramanti L., et al. 2018. Spearfishing modulates flight initiation distance of fishes: the effects of protection, individual size, and bearing a speargun. ICES J. Mar. Sci. 75: 1779-1789. https://doi.org/10.1093/icesjms/fsy059

Whatmough S., Van Putten I., Chin A. 2011. From hunters to nature observers: a record of 53 years of diver attitudes towards sharks and rays and marine protected areas. Mar. Freshw. Res. 62: 755-763.

https://doi.org/10.1071/MF10142 